\title{
Cuidados de enfermagem dispensados ao potencial doador de órgãos em morte encefálica: uma revisão integrativa
}

RESUMO | OBJETIVO: Conhecer os cuidados de enfermagem dispensadas ao potencial doador de órgãos em morte encefálica. MÉTODO: Revisão integrativa que se dividiu em seis etapas. Os critérios de inclusão foram os artigos disponíveis completos e gratuitos, em qualquer idioma visto a grande escassez de estudos na área, publicados entre os anos de 2010 a 2016 . RESULTADOS: Foram encontrados 179 artigos dos quais 17 cumpriram aos critérios estabelecidos e foram incluídos na presente revisão. O conhecimento é essencial para a realização das condutas normalmente realizadas. A abordagem familiar dos potenciais doadores também faz parte das condutas de enfermagem, visto ser uma abordagem multiprofissional. Esse ponto é um dos mais críticos do processo de doação, visto o grande obstáculo interposto pelos familiares. CONCLUSÃO: É de grande importância que o profissional de enfermagem tenha sistematizada as ações que adotará frente a um caso de morte encefálica, principalmente relacionado a conduta com familiares.

Palavras-chaves: Obtenção de Tecidos e Órgãos; Enfermagem; Morte encefálica.

\begin{abstract}
I OBJETIVO: Conhecer os cuidados de enfermagem dispensadas ao potencial doador de órgãos em morte encefálica. MÉTODO: Revisão integrativa que se dividiu em seis etapas. Os critérios de inclusão foram os artigos disponíveis completos e gratuitos, em qualquer idioma visto a grande escassez de estudos na área, publicados entre os anos de 2010 a 2016 . RESULTADOS: Foram encontrados 179 artigos dos quais 17 cumpriram aos critérios estabelecidos e foram incluídos na presente revisão. O conhecimento é essencial para a realização das condutas normalmente realizadas. A abordagem familiar dos potenciais doadores também faz parte das condutas de enfermagem, visto ser uma abordagem multiprofissional. Esse ponto é um dos mais críticos do processo de doação, visto o grande obstáculo interposto pelos familiares. CONCLUSÃO: É de grande importância que o profissional de enfermagem tenha sistematizada as ações que adotará frente a um caso de morte encefálica, principalmente relacionado a conduta com familiares.
\end{abstract}

Keywords: Obtaining Tissues and Organs; Nursing; Brain death.

RESUMEN | OBJETIVO: Conocer la atención de enfermería proporcionada al potencial donante de órganos en la muerte cerebral. METODO: Revisión integrativa que se dividió en seis etapas. Los criterios de inclusión fueron los artículos disponibles completos y gratuitos, en cualquier idioma visto por la gran escasez de estudios en la zona, publicados entre los años 2010 y 2016. RESULTADOS: Encontramos 179 artículos, 17 de los cuales cumplieron con los criterios establecidos y fueron incluidos en esta revisión. El conocimiento es esencial para realizar las conductas que normalmente se realizan. El enfoque familiar de los donantes potenciales también forma parte de las conductas de enfermería, ya que es un enfoque multiprofesional. Este punto es uno de los más críticos del proceso de donación, dado el gran obstáculo que traen los miembros de la familia. CONCLUSION: Es de gran importancia que el profesional de enfermería haya sistematizado las acciones que adoptará ante un caso de muerte cerebral, principalmente relacionadas con la conducta con los miembros de la familia.

Palabras claves: Obtención de tejidos y órganos; Enfermería; Muerte cerebral.

\section{Ana Cássia Alcântara Sindeaux}

Enfermeira graduada pelo Centro Universitário de Juazeiro do Norte - UNIJUAZEIRO. ORCID: 0000-0001-8225-3500

\section{Anderson Marcos Vieira do Nascimento \\ Mestrando em Saúde Pública pela Univer- sidade Estadual da Paraíba - UEPB. Enfer- meira graduada pelo Centro Universitário de Juazeiro do Norte - UNIJUAZEIRO. Membro do Grupo de Pesquisa e estudos em Ciências da Saúde cadastrado no Dire- tório do $\mathrm{CNPq}$. \\ ORCID: 0000-0001-8575-1580}

Recebido em: 20/10/2020

Aprovado em: 16/11/2020

\section{José Rafael Eduardo Campos}

Graduando em Enfermagem pelo Centro Universitário de Juazeiro do Norte - UNIJUAZEIRO. Membro do Grupo de Pesquisa e estudos em Ciências da Saúde cadastrado no Diretório do CNPq e bolsista do Programa Institucional de Bolsas de Iniciação Científica (PIBIC).

ORCID: 0000-0003-0463-4839

\section{Jessika Brenda Rafael Campos}

Enfermeira, Residente Multiprofissional com ênfase em Transplante pelo Hospital Universitário Walter Cantídio - UFC. Membro do Grupo de Pesquisa e estudos em Ciências da Saúde cadastrado no Diretório do CNPq.

ORCID: 0000-0003- 3768-5480

\section{Alyce Brito Barros}

Graduanda em Enfermagem pelo Centro Universitário de Juazeiro do Norte - UNIJUAZEIRO. Membro do Grupo de Pesquisa e estudos em Ciências da Saúde cadastrado no Diretório do CNPq.

ORCID: 0000-0002-2775-1264

\section{Dayse Christina Rodrigues Pereira Luz}

Pós-Doutoranda em Ciências da Saúde pelo Centro Universitário Saúdo do ABC-FMABC. Doutora em Ciências da Saúde pelo Centro Universitário Saúdo do ABC. Mestre em enfermagem pela Universidade Federal do Ceará - UFC. Docente do Centro Universitário de Juazeiro do Norte -UNIJUAZEIRO. Líder do Grupo de Pesquisa e estudos em Ciências da Saúde cadastrado no Diretório do CNPq. ORCID: 0000-0002-5719-3574. 
1 o Brasil o processo de doação de órgãos teve início em 1964, sendo aprimorado com a ajuda das novas tecnologias e pesquisas na área. Com isso houve necessidade de regulamentação do processo de doação, surgindo assim as leis que regulam todo o processo, e com o objetivo de otimizar os resultados almejados em relação a doação e captação de órgãos ${ }^{(1)}$.

O Conselho Federal de Medicina através da resolução CFM n ${ }^{\circ}$ 1.480/97 estabelece os critérios de morte encefálica, sendo caracterizada pela parada irreversível das funções respiratórias e circulatórias ou cessação de todas as funções cerebrais incluindo tronco cerebral, sendo fruto de um processo irreversível com o estabelecimento de causa conhecida e, constatada de modo indiscutível, seus sinais clínicos são, coma irreversível, arreativo e aperceptivo, com ausência de atividade motora supra espinal e apneia, sendo confirmada por exames clínicos complementares dentro de intervalos de tempo próprio para cada faixa etária ${ }^{(2)}$.

Morte encefálica é um processo que começa com isquemia cerebral, apresenta sinais clínicos iniciais evidenciados por, hipertensão arterial sistêmica, bradicardia e bradipnéia, presente em $25 \%$ dos pacientes, indicando falência sistêmica com origem na má perfusão cerebral, quando a lesão aumenta a atividade vagal é interrompida, originando uma descarga adrenérgica de curta duração, taquicardia, hipertensão, hipertermia e aumento do debito cardíaco, eleva-se a pressão intracraniana a tal ponto que pode haver herniação do tronco cerebral, bloqueando completamente a circulação arterial o que determina o quadro clinico de morte encefálica ${ }^{(3)}$.

Entre as principais doenças de base que podem evoluir para morte encefálica estão às causas traumáticas predominante no sexo masculino, doenças cardiovasculares, congênitas ou adquiri-
As alterações clínicas iniciais do processo de morte encefálica podem acarretar danos irreversíveis ao coração como necrose isquêmica miocárdica é arritmias, ocasionados por vasoconstrição e aumento da pressão arterial, após instalação da morte encefálica há mudanças nesses parâmetros, vasodilatação, queda na pressão arterial sistêmica, hipovolemia relativa das que levam a uma internação rápida deixando os familiares diante de uma situação súbita onde ficam fragilizados para tomarem decisões naquele momento referente ao destino dos órgãos de seu familiar. Por isso o apoio psicológico e a escuta qualificado dos profissionais de saúde torna-se imprescindível (1).

As alterações clínicas iniciais do processo de morte encefálica podem acarretar danos irreversíveis ao coração como necrose isquêmica miocárdica é arritmias, ocasionados por vasoconstrição e aumento da pressão arterial, após instalação da morte encefálica há mudanças nesses parâmetros, vasodilatação, queda na pressão arterial sistêmica, hipovolemia relativa, sendo extremamente danoso ao paciente, se não tratados corretamente pode deprimir a função cardíaca com evolução para assistolia ${ }^{(4)}$.

Todo paciente crítico apresenta riscos de infecções, não sendo diferente no potencial doador, por isso medidas devem ser tomadas para minimizar tais eventos adversos. Procedimentos simples como lavagem das mãos e uso de equipamentos de proteção individual são indicados, uma vez que certas infecções podem tornar a doação inviável. Por isso o enfermeiro precisa registrar e identificar os sinais iniciais de infecção informar a equipe de transplante, seguir protocolo clínico de acordo com a instituição, visando uma intervenção rápida para que o processo de doação não seja interrompido e não cause danos aos receptores ${ }^{(5)}$.

A temperatura corporal constitui-se um dos parâmetros mais importantes no potencial doador, e que precisa ser rigorosamente controlada, uma vez que o paciente em morte encefálica perde suas habilidades hemodinâmicas de controlar a temperatura devido a lesão no centro regulador. O paciente torna- se susceptível a perder calor para o ambiente, torna-se inapto a tremer para produzir calor, isso quando associado a grandes infusões de líquidos não aquecidos, a temperatura tende a cair bruscamen- 
te, e a equipe de enfermagem precisa tomar medidas que possam minimizar essa situação, com uso de mantas térmicas, aquecer o ambiente e os gases do ventilador, infundir líquidos aquecidos, monitorar a temperatura para prevenir danos decorrentes da hipotermia ${ }^{(6)}$.

Pacientes que são portadores de doenças crônicas ou outras comorbidades que comprometem sua qualidade de vida tem a chance de receber um órgão e ser curado. Os transplantes desde o seu surgimento têm ajudado a salvar miIhares de pacientes, tendo em vista que um único potencial doador pode doar múltiplos órgãos beneficiando vários pacientes. Devido a avanços nas novas tecnologias o índice de aceitação de órgãos cresceu, bem como a sobrevida dos pacientes transplantados. Mas é necessário considerar a conduta dos profissionais que prestam assistência ao paciente assim como a família. Nessa perspectiva entra o papel da enfermagem que desenvolve tantas ações técnicas com os pacientes assim como adquire papel fundamental no contexto familiar ${ }^{(7)}$.

Nesse estudo levantaram-se as seguintes indagações: seriam os enfermeiros preparados para prestar assistência ao potencial doador de órgãos? Será que a assistência prestada pelos enfermeiros contribui de forma significativa para efetividade da doação de órgãos? Partindo do pressuposto que uma boa assistência aumenta a efetivação das doações, esse trabalho justifica-se em conhecer a atuação do profissional enfermeiro no manejo com o potencial doador identificando previamente os sinais clínicos de morte encefálica e quais ações cabíveis ante as alterações hemodinâmicas dos mesmos ${ }^{(8)}$.

Assim destaca-se a relevância deste estudo em conhecer as condutas de enfermagem na manutenção do potencial doador, uma vez que este profissional é o responsável direto pelos cuidados com o paciente critico pela vigilância continua do potencial doador, agindo para que não ocorra alterações hemodi- nâmica, nem paradas cardíacas antes da retirada dos órgãos, tão crucial na viabilidade dos órgãos doados e na qualidade de vida do receptor.

O conhecimento teórico e aplicação prática que o profissional possui é essencial para a exequibilidade de uma boa implementação da assistência. O nível de preparação seja adquirido na academia ou mesmo durante a prática assistencial são determinantes na objetividade e assertividade das ações. Esse fato é ainda mais imprescindível quando se trata de doação de órgãos, visto que a assistência não é somente prestada com o paciente, mas principalmente com os familiares, peça chave no processo.

Mais de $40 \%$ das famílias se negam a doar os órgãos de um familiar. Esse achado pode estar ligado a diversos fatores, mas a abordagem psicológica associada ao conhecimento do profissional sobre a situação e melhor método de abordagem pode ser decisiva. Responder a possíveis questionamentos de forma clara é um manejo estratégico e necessário para uma tomada de decisão o mais coerente possível por parte da família ${ }^{(9)}$.

Desse modo o objetivo do estudo foi conhecer as condutas de enfermagem dispensadas ao potencial doador de órgãos em morte encefálica na literatura científica.

\section{MÉTODO}

Trata-se de um estudo realizado por meio do método de revisão integrativa da literatura. O estudo ora proposto utilizou o modelo descrito por Mendes, Silveira e Galvão ${ }^{(10)}$, o qual se dividiu em seis etapas: a) Primeira etapa: identificação do tema e seleção da hipótese para a elaboração da revisão integrativa; b) Segunda etapa: estabelecimento de critérios para inclusão e exclusão de estudos/ amostragem e busca na literatura; c) Terceira etapa: definição das informações a serem extraídas dos estudos selecionados/categorização dos estudos; d) Quarta etapa: avaliação dos estudos incluídos na revisão integrativa; e) Quinta etapa: interpretação dos resultados; f) Sexta etapa: apresentação da revisão/ síntese do conhecimento.

A primeira etapa foi constituída na seleção da hipótese através das seguintes perguntas norteadoras: seriam os enfermeiros preparados para prestar assistência ao potencial doador de órgãos? Será que a assistência prestada pelos enfermeiros contribui de forma significativa para efetividade da doação de órgãos?

A segunda etapa se deu através do estabelecimento dos critérios de inclusão e exclusão a fim de nortear a busca e seleção dos artigos. Os critérios de inclusão foram os artigos disponíveis completos e gratuitos, em qualquer idioma visto a grande escassez de estudos na área, publicados entre os anos de 2010 a 2016. A escolha temporal ocorreu pelo fato de que em 2010 houve o lançamento de diretrizes específicas para doadores de órgãos, o que fez aumentar o número de estudos e atenção com a temática uma vez que, antes da publicação dessas diretrizes, a publicação acerca do tema era escassa. Os critérios de exclusão foram os que apresentassem baixa classificação metodológica.

As bases de dados eleitas para a busca dos artigos foram: Medical Literature Analysis and Retrieval System Online (MEDLINE), Literatura Latino-Americana e do Caribe em Ciências da Saúde (LILACS), Scientific Electronic Library Online (SciELO) e Base de Dados de Enfermagem (BDENF). Os descritores de saúde utilizados: Obtenção de Tecidos e Órgãos; Enfermagem e Morte encefálica utilizando o operador Booleano AND.

A terceira etapa foi constituída pela extração de informações de autor e ano, objetivo, desfecho, condutas de enfermagem, qualidade metodológica do estudo pela ferramenta de análise de artigos proposta por Keynes ${ }^{(11)}$ e nível de evidência. A quarta etapa deu-se através da classificação do nível de evidência dos artigos, proposto por Pompeo, Rossi 


\section{Figura I: Fluxograma de busca de estudos}

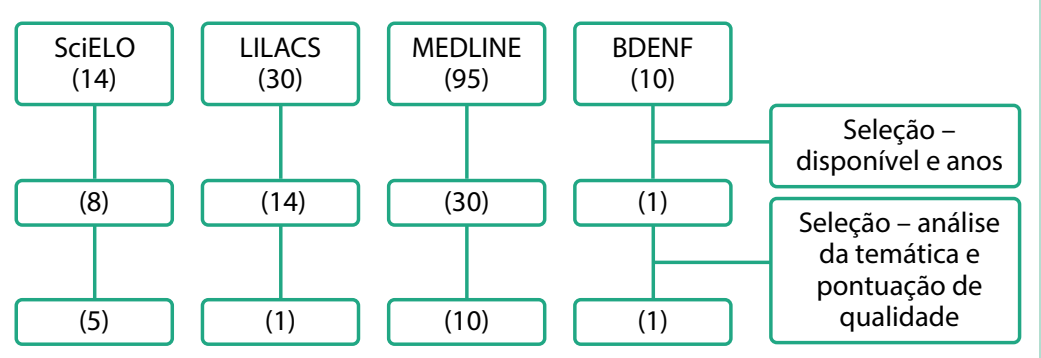

Fonte: Elaborada pela autora

Tabela I: Distribuição eletrônica e de localidade dos estudos

\section{Característica do estudo}

Inglês

Português

MEDLINE

SCIELO

LILACS

BDENF

TOTAL

Fonte: Elaborada pela autora e Galvão ${ }^{(12)}$, do nível de melhor qualidade de evidência. A quinta etapa, ocorreu por meio das interpretações dos artigos e síntese dos resultados e a sexta etapa foi elaborado um artigo com a finalidade de divulgar os resultados obtidos.

\section{RESULTADOS}

Foram encontrados 149 artigos dos quais 17 cumpriram aos critérios estabelecidos e foram incluídos na presente revisão. A figura abaixo ilustra os passos metodológicos para se chegar aos artigos que foram inseridos.

A tabela seguinte contém as informações quantitativas dos estudos incluídos na revisão.

O quadro seguinte contém algumas informações extraídas dos estudos incluídas na presente revisão.

\section{DISCUSSÃO}

A enfermagem precisa manter a monitorização hemodinâmica, com pressão

Quadro l: características do estudo

\begin{tabular}{|c|c|c|c|c|c|}
\hline Artigo & Objetivo & Desfecho & Condutas de enfermagem & $\begin{array}{l}\text { Qualidade } \\
\text { metodológica }\end{array}$ & $\begin{array}{l}\text { Nível de } \\
\text { evidência }\end{array}$ \\
\hline 13 & $\begin{array}{l}\text { Analisar os fatores relacionados à } \\
\text { estrutura, ao processo e resultados } \\
\text { da doação de órgãos e tecidos } \\
\text { para transplantes }\end{array}$ & $\begin{array}{l}\text { Possivelmente, a estrutura e o pro- } \\
\text { cesso determinaram o resultado de } \\
\text { que } 72,3 \% \text { dos potenciais doadores } \\
\text { não efetivaram a doação }\end{array}$ & Registros adequados & 8 & VI \\
\hline 14 & $\begin{array}{l}\text { Avaliar o nível de conhecimento, } \\
\text { consciência e atitudes de direito, } \\
\text { teologia, enfermagem e estudan- } \\
\text { tes de comunicação médicas, que } \\
\text { estarão envolvidos nesta questão } \\
\text { no futuro, em relação à morte } \\
\text { cerebral e doação de órgãos }\end{array}$ & $\begin{array}{l}\text { Uma melhor compreensão da } \\
\text { doação de órgãos e conceitos pelos } \\
\text { profissionais médicos, enfermeiros, } \\
\text { legisladores, funcionários religiosos } \\
\text { e de comunicação }\end{array}$ & $\begin{array}{l}\text { Obter mais conhecimento da } \\
\text { temática }\end{array}$ & 8 & $\mathrm{VI}$ \\
\hline 1 & $\begin{array}{l}\text { Verificar o conhecimento do enfer- } \\
\text { meiro no processo de doação de } \\
\text { órgãos e tecidos para transplantes }\end{array}$ & $\begin{array}{l}\text { Os enfermeiros apresentaram consi- } \\
\text { derável conhecimento em relação } \\
\text { ao processo de doação }\end{array}$ & $\begin{array}{l}\text { Obter mais conhecimento da } \\
\text { temática }\end{array}$ & 6 & VI \\
\hline 9 & $\begin{array}{l}\text { Verificar a influência da estrutura e } \\
\text { processo na efetividade da doação } \\
\text { de órgãos e tecidos }\end{array}$ & $\begin{array}{l}\text { A adequação dos fatores relacio- } \\
\text { nados à estrutura e processo está } \\
\text { associada à efetividade da doação }\end{array}$ & $\begin{array}{l}\text { Melhorar estrutura organiza- } \\
\text { cional e humano }\end{array}$ & 8 & VI \\
\hline 4 & $\begin{array}{l}\text { Estudar as atitudes dos funcio- } \\
\text { nários do hospital no sentido de } \\
\text { doação e transplante de órgãos }\end{array}$ & $\begin{array}{c}\text { A atual perda de confiança em } \\
\text { doação e transplante de órgãos } \\
\text { também afeta a atitude do pessoal } \\
\text { médico }\end{array}$ & Efetivar uma atitude positiva & 8 & VI \\
\hline
\end{tabular}




\begin{tabular}{|c|c|c|c|c|c|}
\hline 15 & $\begin{array}{l}\text { Conhecer o significado da ação } \\
\text { de enfermeiros no processo de } \\
\text { doação para viabilizar órgãos e } \\
\text { tecidos para transplante }\end{array}$ & $\begin{array}{l}0 \text { conhecimento da vivência dos } \\
\text { enfermeiros nesse processo oferece } \\
\text { subsídios aos profissionais de saúde }\end{array}$ & $\begin{array}{l}\text { Mudar paradigmas, humanizar o } \\
\text { processo de doação }\end{array}$ & 10 & $\mathrm{VI}$ \\
\hline 5 & $\begin{array}{c}\text { Identificar as necessidades educa- } \\
\text { cionais no processo de doador de } \\
\text { órgãos }\end{array}$ & $\begin{array}{l}0 \text { treinamento fornecido por } \\
\text { colegas experientes e uma cultura } \\
\text { que incentiva a discussão sobre } \\
\text { aspectos do processo de doador } \\
\text { pode desenvolver a competência } \\
\text { profissional dos enfermeiros }\end{array}$ & $\begin{array}{l}\text { Ter vasta experiência ou competência } \\
\text { e formação em doação de órgãos }\end{array}$ & 8 & VI \\
\hline 16 & $\begin{array}{l}\text { Estudar as percepções de suas } \\
\text { experiências de responsabilidades } \\
\text { profissionais e aspectos organiza- } \\
\text { cionais }\end{array}$ & $\begin{array}{c}\text { A ambiguidade e várias percepções } \\
\text { de diagnóstico de morte encefálica } \\
\text { parece ser um aspecto crucial ao } \\
\text { cuidar de um paciente com morte } \\
\text { cerebral }\end{array}$ & $\begin{array}{l}\text { A percepção das enfermeiras da UTI } \\
\text { de (1) a sua responsabilidade pro- } \\
\text { fissional, (2) o papel da organização } \\
\text { sobre doação de órgãos }\end{array}$ & 8 & $\mathrm{VI}$ \\
\hline 17 & $\begin{array}{l}\text { Analisar a opinião dos enfermeiros } \\
\text { sobre os cuidados de enfermagem } \\
\text { ao paciente em morte encefálica e } \\
\text { potencial doador de órgãos. }\end{array}$ & $\begin{array}{l}0 \text { cuidado de enfermagem ao po- } \\
\text { tencial doador de órgãos configu- } \\
\text { ra-se como um processo complexo } \\
\text { e que requer melhor qualificação e } \\
\text { maturidade emocional, nem sempre } \\
\text { presente. }\end{array}$ & Conduta assistencial & 8 & $\mathrm{VI}$ \\
\hline 18 & $\begin{array}{c}\text { Analisar as responsabildades do } \\
\text { enfermeiro no transplante de } \\
\text { órgãos }\end{array}$ & $\begin{array}{l}0 \text { enfermeiro deve ter conhecimen- } \\
\text { to dos princípios de boas práticas e } \\
\text { ter recursos disponíveis para avaliar } \\
\text { o mérito, riscos e questões sociais } \\
\text { relacionadas aos transplantes. }\end{array}$ & $\begin{array}{l}\text { Controle de qualidade do cuidado } \\
\text { ministrado, colaboração entre os } \\
\text { profissionais envolvidos, implemen- } \\
\text { tação de estratégias voltadas para } \\
\text { a educação em saúde, realização de } \\
\text { pesquisas oriundas de problemas } \\
\text { vivenciados na prática clínica, e a } \\
\text { organização e registro relacionados } \\
\text { ao cuidado prestado }\end{array}$ & 8 & VI \\
\hline 8 & $\begin{array}{l}\text { Compreender as experiências e } \\
\text { expectativas dos enfermeiros de } \\
\text { unidades de terapia intensiva no } \\
\text { cuidado ao doador de órgãos para } \\
\text { transplantes e à sua família. }\end{array}$ & $\begin{array}{l}0 \text { cotidiano dos enfermeiros de } \\
\text { terapia intensiva no cuidado às } \\
\text { famílias e aos doadores de órgãos } \\
\text { é permeado por obstáculos que } \\
\text { interferem no processo de doação }\end{array}$ & Estabelecer empatia e a comunicação & 10 & $\mathrm{VI}$ \\
\hline 2 & $\begin{array}{l}\text { Apresentar um modelo teórico } \\
\text { de organização do cuidado ao } \\
\text { paciente em morte encefálica e o } \\
\text { processo de doação de órgãos }\end{array}$ & $\begin{array}{c}\text { O modelo apresentado configura-se } \\
\text { como um referencial disponível } \\
\text { para validação e aplicação pelos } \\
\text { profissionais }\end{array}$ & $\begin{array}{l}\text { Produção a partir de ciclos de plane- } \\
\text { jamentos e criação de um ambiente } \\
\text { propício para o sucesso da sua } \\
\text { implementação }\end{array}$ & 6 & VI \\
\hline 3 & $\begin{array}{l}\text { Descrever a atuação do enfermeiro } \\
\text { na assistência para manutenção } \\
\text { fisiológica de um potencial doador } \\
\text { de órgãos }\end{array}$ & $\begin{array}{l}\text { É essencial que o enfermeiro tenha } \\
\text { conhecimentos sobre as possíveis } \\
\text { alterações fisiopatológicas resultan- } \\
\text { tes da morte encefálica }\end{array}$ & $\begin{array}{l}\text { Manutenção fisiológica do potencial } \\
\text { doador de órgãos }\end{array}$ & 8 & $\mathrm{Vl}$ \\
\hline 19 & $\begin{array}{l}\text { Analisar diretrizes para manu- } \\
\text { tenção de múltiplos órgãos no } \\
\text { potencial doador adulto falecido }\end{array}$ & $\begin{array}{l}\text { A avaliação da função hepática, } \\
\text { assim como o controle metabólico } \\
\text { e a realização de sorologias virais } \\
\text { são fundamentais para a orientação } \\
\text { das equipes transplantadoras }\end{array}$ & $\begin{array}{l}\text { Manutenção fisiológica do potencial } \\
\text { doador de órgãos }\end{array}$ & 8 & VI \\
\hline
\end{tabular}




\begin{tabular}{|c|c|c|c|c|c|}
\hline 20 & $\begin{array}{c}\text { Identificar experiências e } \\
\text { sentimentos sobre o processo } \\
\text { de doação de órgãos, a partir da } \\
\text { perspectiva de um parente de um } \\
\text { doador de órgão em uma unidade } \\
\text { de transplante }\end{array}$ & $\begin{array}{c}\text { O estudo identificou a necessidade } \\
\text { de prestar apoio social e emocional } \\
\text { para as famílias que enfrentam a } \\
\text { experiência do processo de doação } \\
\text { de órgãos }\end{array}$ & Sensibilidade e apoio sócio-emocional & 8 & $\mathrm{VI}$ \\
\hline 7 & $\begin{array}{l}\text { Desvelar a percepção dos } \\
\text { profissionais que atuam em Or- } \\
\text { ganizações de Procura de Órgãos } \\
\text { sobre os fatores que facilitam e } \\
\text { dificultam a entrevista familiar no } \\
\text { processo de doação de órgãos e } \\
\text { tecidos para transplante. }\end{array}$ & $\begin{array}{l}\text { Os fatores que facilitam e dificul- } \\
\text { tam a entrevista familiar estão } \\
\text { relacionados ao local da entrevista, } \\
\text { à assistência prestada ao potencial } \\
\text { doador e aos familiares, aos escla- } \\
\text { recimentos fornecidos à família e a } \\
\text { manifestação do potencial doador } \\
\text { em vida sobre a decisão quanto à } \\
\text { doação de órgãos. }\end{array}$ & Assistência eficaz a família & 10 & $\mathrm{VI}$ \\
\hline
\end{tabular}

dentro da normalidade, sendo preferencialmente controlado de forma invasiva, a infusão de cristaloides aquecidos seria uma das medidas para o controle, verificar sinais de hipofluxo e as medidas da pressão venosa central (PVC). As arritmias serão controladas mediante a correção dos demais parâmetros hemodinâmicos ${ }^{(19)}$.

O conhecimento e habilidade são essenciais para a realização das condutas normalmente implementadas. Engloba a assistência prestada ao paciente no setor em que se encontra geralmente terapia intensiva, atendimento de necessidades fisiológicas além de participar e gerenciar, executar e coordenar procedimento de enfermagem. Nesse sentido, a Sistematização da Assistência de Enfermagem deve ser aplicada para maior segurança de condutas que viabilizem a doação ${ }^{(3)}$.

Ademais, o embasamento teórico-prático sobre morte encefálica e seus sinais são de grande importância não só no atendimento integral do paciente, como pode melhor nortear uma conversa franca com familiares em questionamentos que possam surgir. Uma insegurança percebida pelo familiar pode determinar a aceitação ou rejeição de uma doação em potencial ${ }^{(8)}$.

Pode-se notar que o domínio que o profissional possui sobre a situação pode ser determinante sob diversos aspectos que podem influenciar significativamente

a decisão de doação. A repercussão das diversas abordagens seja no aspecto fisiológico com o paciente seja no aspecto psicológico e esclarecedor que o profissional adota se revela na porcentagem de sucesso em uma doação de órgãos ${ }^{(18)}$.

De acordo com os efeitos fisiológi-

De acordo com os efeitos fisiológicos que podem ocorrer em uma morte encefálica, é essencial que o profissional de enfermagem reconheça sinais de complicações de determinados órgãos. cos que podem ocorrer em uma morte encefálica, é essencial que o profissional de enfermagem reconheça sinais de complicações de determinados órgãos. Esse fato possibilita a adoção de manejo precoce para correção e preservação do órgão. Para a equipe de enfermagem é essencial reconhecer as alterações hemodinâmicas, aspecto que não deve ser subjugado ${ }^{(17)}$.

A abordagem familiar dos potenciais doadores também faz parte das condutas de enfermagem, visto ser uma abordagem multiprofissional. Esse ponto é um dos mais críticos do processo de doação, visto o grande obstáculo interposto pelos familiares. O trabalho com a família, respeitando seus limites é essencial para boa efetivação do transplante ${ }^{(6)}$.

$\mathrm{Na}$ maioria dos locais, há um determinado protocolo de manejo dos pacientes com morte encefálica e potenciais doadores. Esses protocolos além de fornecerem informações sobre o processo de doação em si dos tecidos, podem versar sobre rotinas relacionadas as famílias envolvendo entrevistas, recusas e esclarecimento sobre os processos ${ }^{(4)}$. 
Uma abordagem mais assertiva depende do conhecimento e experiências profissionais ou pessoais vivenciados. Quanto mais abordagem o profissional tiver realizado mais ele será capaz de reconhecer precocemente possíveis dificuldades familiares normalmente evidenciadas as quais podem ser contornadas, tenuamente, e potencializar a possível doação ${ }^{(13)}$.

Nesse processo, as condutas adotadas devem estar pautadas no princípio da humanização da assistência, pensando nos diversos fatores que envolvem os sujeitos e em um cuidar digno. Esse processo adquire ainda mais importância no tocante a abordagem da família em que aspectos bioéticos podem emergir ${ }^{(15)}$.
CONCLUSÃO

O enfermeiro lida com sentimentos como insegurança, medo, angústia, raiva e o processo de luto enfrentado pelos familiares, nesse momento ele precisa de experiência prática para atender de forma acolhedora familiares envolvendo no processo de doação, percebendo sentimentos.

Em muitas situações os profissionais desconhecem integralmente a realização dessas práticas o que é visto como um grande problema visto a importância da efetividade das condutas. Nesse sentido, é essencial que os profissionais sejam melhores orientados o que pode ser realizado com mais ações de educação permanente em saúde para esses profissionais. Isso permitirá, que melhores estratégias profissionais frente a essa situação sejam implementadas assim como a obtenção de melhores resultados possíveis.

É de grande importância que o profissional de enfermagem tenha sistematizada as ações que adotará frente a um caso de morte encefálica, principalmente relacionado a conduta referente as famílias, pelo fato da decisão de doação ou não ser realizada pelos membros familiares. Outras condutas mais técnicas também são executadas e deve ser apreendida e realizada da melhor maneira possível para obtenção de uma máxima efetividade das ações implementadas e desejadas pelo serviço de saúde e de quem depende do órgão transplantado.

\section{Referências}

1. Doria DL, Leite PMG, Brito FPG, Brito GMG, Resende GGS, Santos FLLSM. Conhecimento do enfermeiro no processo de doação de órgãos. Enferm. foco (Brasília). 2015; v. 6, n. 1/4, p. 31-35.

2. Pestana AL, Santos JLG, Erdmann RH, Silva EL, Erdmann AL. Pensamento Lean e cuidado do paciente em morte encefálica no processo de doação de órgãos. Revista da Escola de Enfermagem da USP. 2012; v. 47, n. 1, p. 258-264. http://dx.doi.org/10.1590/S0080-62342013000100033

3. Santana MA, Clênia CD, Espíndula BM. Assistência de enfermagem na manutenção do potencial doador de órgãos. Revista Eletrônica de Enfermagem do Centro de Estudos de Enfermagem e Nutrição. 2010; n. 1, p. 1-15.

4. Grammenos D, Bein T, Briegel J, Eckardt K-U, Gerresheim G, Lang C, et al. Einstellung von potenziell am Organspendeprozess beteiligten Ärzten und Pflegekräften in Bayern zu Organspende und Transplantation. DMW - Deutsche Medizinische Wochenschrift [Internet]. Georg Thieme Verlag KG; 2014; 139(24):1289-94. https://doi.org/10.1055/s-0034-1370107

5. Meyer K, Bjork IT, Eide H. Intensive care nurses' perceptions of their professional competence in the organ donor process: a national survey. Journal of Advanced Nursing. 2012; v. 68, n. 1, p. 104-115. https://doi.org/10.1111/j. 1365-2648.2011.05721.x

6. Formanek M, Schöffski O. Difficulties With the Organ Donation Process in Small Hospitals in Germany. Transplantation Proceedings. 2010; v. 42, n. 5, p. 1445-1448.DOI:10.1016/j.transproceed.2010.01.067

7. Santos MJ, Massarollo MCKB. Fatores que facilitam e dificultam a entrevista familiar no processo de doação de órgãos e tecidos para transplante. Acta paul. enferm., São Paulo. 2011; v. 24, n. 4, p. 472-478.

8. Moraes EL, Neves FF, Santos MJ, Merighi MAB, Massarollo MCKB. Experiências e expectativas de enfermeiros no cuidado ao doador de órgãos e à sua família. Rev. esc. enferm. USP, São Paulo. 2015; v. 49, n. spe2, p. 129-135. DOl: 10.1590/50080-623420150000800018

9. Freire ILS, Vasconcelos QLDAQ, Melo GSM, Torres GV, Araújo EC, Miranda FAN. Facilitating aspects and barriers in the effectiveness of donation of organs and tissues. Texto contexto - enferm., Florianópolis. 2014; v. 23, n. 4, p. 925-934.http://dx.doi.org/10.1590/0104-07072014002350013

10. Mendes KDS, Silveira RCCP, Galvão CM. Revisão integrativa: método de pesquisa para a incorporação de evidencias na saúde e na enfermagem. Texto Contexto Efer, Florianópolis. 2008; v. 17, n.4, p. 758-64. http://dx.doi. org/10.1590/S0104-07072008000400018
11. Keynes M. Primary Care Trust. Critical Appraisal Skills Programme (CASP) Making sense of evidence. London (UK): Oxford; 2002.

12. Pompeo DA, Rossi LA, Galvão CM. Revisão integrativa: etapa inicial do processo de validação de diagnóstico de enfermagem. Acta Paul Enferm. 2009; v. 22, n.4, p. 434-8. http://dx.doi.org/10.1590/\$0103-21002009000400014

13. Freire ILS, Vasconcelos QLDAQ, Torres GV, Araújo EC, Costa IKF, Melo GSM. Structure, process and outcomes of organ and tissue donation for transplantation. Rev Bras Enferm. 2015;68(5):555-63. DOI: http://dx.doi.org/10.1590/ 0034-7167.2015680511i

14. Kocaay AF, Celik SU, Eker T, Oksuz NE, Akyol C, Tuzuner A. Brain Death and Organ Donation: Knowledge, Awareness, and Attitudes of Medical, Law, Divinity, Nursing, and Communication Students. Transplantation Proceedings. 2015; v. 47, n. 5, p. 1244-1248. DOI:10.1016/j.transproceed.2015.04.071

15. Moraes EL, Santos MJ, Merighi MAB, Massarollo MCKB. Experience of nurses in the process of donation of organs and tissues for transplant. Rev. Latino-Am. Enfermagem, Ribeirão Preto. 2014; v. 22, n. 2, p. 226-233. DOI: 10.1590/0104-1169.3276.2406

16. Flodén A, Berg M, Forsberg A. ICU nurses' perceptions of responsibilities and organisation in relation to organ donation-A phenomenographic study. Intensive and Critical Care Nursing. 2011; v. 27, n. 6, p. 305-316. DOI:10.1016/j.iccn.2011.08.002

17. Cavalcante LP, Ramos IC, Araújo MA, Alves MD, Braga VA. Cuidados de enfermagem ao paciente em morte encefálica e potencial doador de órgãos. Acta paul. Enferm. 2014; v. 27, n. 6, p. 567- 572. http://dx.doi.org/10.1590/19820194201400092

18. Mendes KDS, Roza BA, Barbosa SFF, Schirmer J, Galvão CM. Transplante de órgãos e tecidos: responsabilidades do enfermeiro. Texto contexto - enferm., Florianópolis. 2012; v. 21, n. 4, p. 945-953. http://dx.doi.org/10.1590/S010407072012000400027

19. Westphal GA, Caldeira Filho M, Vieira KD, Zaclikevis VR, Bartz MCM, Wanzuita $R$, et al. Diretrizes para manutenção de múltiplos órgãos no potencial doador adulto falecido: Parte III. Recomendações órgãos específicas. Revista Brasileira de Terapia Intensiva. 2010; v. 23, n. 4, p. 410-425. http://dx.doi. org/10.1590/S0103-507X2011000400005.

20. Fernandes MEN, Bittencourt ZZLC, Boin IFSF. Experiencing organ donation: feelings of relatives after consent. Rev. Latino-Am. Enfermagem, Ribeirão Preto. 2015; v. 23, n. 5, p. 895-901. DOI: 10.1590/0104-1169.0486.2629. 